\title{
Plants and Health: New Perspectives on the Health-Environment-Plant Nexus. Edited by Elizabeth Anne Olson and John Richard Stepp. 2016. Springer, Switzerland. 175 pp.
}

\author{
Alex McAlvay ${ }^{1 *}$ \\ ${ }^{1}$ Department of Botany, University of Wisconsin-Madison, Madison, Wisconsin, USA. \\ *alexmcalvay@gmail.com
}

Received September 6 , 2017

Accepted September 10, 2017

OPEN $\partial_{\text {ACCESS }}$
DOI 10.14237/ebl.8.1.2017.1100

Copyright (c) 2017 by the author(s) licensee Society of Ethnobiology. This is an open-access article distributed under the terms of the Creative Commons Attribution-NonCommercial 4.0 International Public License (https://creativecommons.org/licenses/by-nc/4.0), which permits non-commercial use, distribution, and reproduction in any medium, provided the original author and source are credited.

Plants and Health is comprised of ethnographic case studies which harness recent theoretical developments in anthropology and extend the field of ethnobotany still further beyond its origins in lists of plant uses. Emerging from a session at the 2014 American Anthropological Association meeting with a similar name, the authors use examples of planthuman interactions to explore medical pluralism, tradition, authenticity, health sovereignty, neoliberalism, ontology, and other themes.

This volume stands out for three major contributions. First, it embraces the complexity arising at cultural interfaces by engaging with dynamic medical pluralism. Second, it demonstrates the rich potential of ethnobiology to be informed by, and contribute to, theoretical trends in anthropology such as multispecies ethnography and the ontological turn. Third, it investigates the nuanced relationships of neoliberalism, the state, and human interactions with medicinal plants with sometimes surprising outcomes.

Plants and Health departs from oversimplified narratives on globalization, binary indigenous/ biomedical modes of healing, and monolithic constructs of "medical knowledge," instead engaging with the complexity of interacting medical systems. Olson (Chapter 5) argues that terms like "cultural diffusion," "colonization," and "cultural borrowing," are insufficient to characterize the processes involved in the translation of healing systems across cultures. Anderson (Chapter 1) invokes Latour's (2004) actornetwork theory to interpret these dynamic hybridities. Anderson (Chapter 1), Bridges (Chapter 4), Olson (Chapter 5), and Ferenczi (Chapter 6) all demonstrate cases from Latin America where elements of different health systems are selectively adopted in a piecemeal fashion, while LaPlante (Chapter 2) asserts that "Javanese" medicine is actually the result of cultural layerings of Animist, Hindu, Buddhist, Islamic, and bioscientific components. Stepp (Chapter 7) propounds the idea of importing diversity indices from ecology to better understand the asymmetrical distribution of medicinal plant knowledge in and across communities.

Plants and Health also provides an important update to anthropological theory in ethnobiology. While the recent works of ontological and multispecies anthropologists like Kohn, Tsing, and Viveiros de Castro depend heavily on examples of human-plant and human-environment interactions, ethnobiology as a discipline is rarely explicitly mentioned and certainly not foregrounded in their discourse. This volume takes steps to actualize the potential contributions of ethnobiology to these movements. Nearly every chapter thoroughly treats ontologies surrounding the body, causality of disease, diagnosis, and treatment. LaPlante (Chapter 2) applies the "becomings" of Deleuze and Guattari and Ingold's (2011) interpretation of Lefebvre's "meshwork" to emphasizes the interpermeability of the barriers differentiating women from the plant medicines they express juice from. Ferenczi (Chapter 6) also draws on "becomings" and "meshwork" to fruitfully explore the entanglements of Bribri, AfroCaribbean, Tica, and western Canadian ontologies of people and plants. Anderson (Chapter 1), LaPlante (Chapter 2) and Bridges (Chapter 4) dissect nuanced 
(if not untranslatable) health concepts like $i k$ ' among the Yucatec of Mexico, rasa in Java, as well as samay and shinshiyachina among the Runa of Ecuador. These same authors argue that western biomedicine fails to acknowledge the multidimensional benefits to wellbeing arising from plant-human interactions. LaPlante (Chapter 2) and Bridges (Chapter 4) highlight local concepts of strengthening and health maintenance from plants that depart from treatmentcentric ontologies, and Bridges (Chapter 4) demonstrates how medicinal plants strengthen social ties as well as physical bodies in Napo Runa communities.

The volume also deftly examines the roles of neoliberalism, globalization, and the state in humanplant relationships. In the complimentary works of McNamara (Chapter 3) and Bridges (Chapter 4), we see examples of sometimes counterintuitive consequences of neoliberalism and market economies on empowerment and disempowerment. McNamara argues that the Bangladeshi government and certain NGOs are acting in a neoliberal manner by encouraging citizens to become self-sufficient in medicinal plant production and consumption. On first sight, this appears to be empowering, but McNamara (Chapter 3) argues that this is a neoliberal reassignment of responsibility for healthcare to individuals by an inadequate state. Bridges (Chapter 4) demonstrates how employing ethnomedical knowledge to treat illnesses arising from wage labor is a galvanizing act of resistance in Ecuadorian Napo Runa communities. Ferenczi (Chapter 6) politicizes colonial and decontextualized ethnomedical tourism in Costa Rica and its impacts on ontologies of nature and culture.

As a whole, this volume positions ethnobiology as a rich realm for leading edge anthropological inquiry in cultural interchange, ontology, and political economy. The complimentary expertise of Olson and Stepp enhance the volume and the lively, diverse offerings of the chapters are stimulating both individually and taken together as a complete work. Each chapter adds nuance and challenge to monolithic concepts in ethnomedicine and global health, portending a dozen future lines of inquiry for anthropological ethnobotany.

\section{References Cited}

Ingold, T. 2011. Being Alive: Essays on Movement, Knowledge and Description. Routledge, London and New York, NY.

Latour, B. 2004. Politics of Nature: How to Bring the Sciences into Democracy. C. Porter, trans. Harvard University Press, Cambridge, MA. 